\title{
Optical and Defect Properties in Nearly Stochiometry ZnO Film Coated on Si (111) by Ultrasonic Spray Pyrolysis Method
}

Bambang Soegijono $^{1 *}$, Hamdan Akbar Notonegoro ${ }^{2}$, Iwan Sugihartono ${ }^{3}$, Emil Budianto ${ }^{4}$, Muhamad Riza $^{2}$ Iskandar $^{5}$

${ }^{1}$ Departement of Physics, Universitas Indonesia

Depok, Indonesia

Email : bambangsg11 [AT] yahoo.com

${ }^{2}$ Dept of Mechanical Engineering, Universitas Sultan Ageng Tirtayasa

Cilegon, Indonesia

Email : hamdan_an [AT] untirta.ac.id

${ }^{3}$ Departement of Physics, Universitas Negeri

Jakarta, Indonesia,

Email : isugihar [AT] hotmail.com

${ }^{4}$ Departement of Chemistry, Universitas Indonesia

Depok, Indonesia

Email : emilb [AT] ui.ac.id

${ }^{5}$ Central Facility for Electron Microscope, RWTH Aachen University

Aachen, Germany

Email : Iskandar [AT] gfe.rwth-aachen.de

${ }^{*}$ Corresponding author's email : bambangsg11 [AT] yahoo.com

\begin{abstract}
ZnO is one of ceramic semiconductor material, which has interesting properties due its wide bandgap energy $(3.4 \mathrm{eV}$ ), and it may be used in many optoelectronic devices. Optical and Defects properties of ZnO could affect the properties of the devices. ZnO films have been deposited on Si (111) substrate by ultrasonic spray pyrolysis (U.S.P.) method at temperatures $400^{\circ} \mathrm{C}, 450^{\circ} \mathrm{C}$, and $500^{\circ} \mathrm{C}$. The samples consist of two part, annealed and nonannealed heat treatment. The annealed treatment was conducted at temperature $800^{\circ} \mathrm{C}$ for 2 hours. The XRD pattern revealed that the $\mathrm{ZnO}$ film is a polycrystalline. The T.E.M. characterization showed that non stochiometry of the $\mathrm{ZnO}$ film present. From the $U V$-vis pattern, the transition of electrons is affected by the defect present. The ZnO films show a characteristic luminescence properties. It found three defects, there are oxygen vacancies $\left(V_{o}\right)$, oxygen interstitial $\left(O_{i}\right)$, and an electron transition from the level of the ionized oxygen vacancies to the valence band, that is responsible for green band emission.
\end{abstract}

Keywords - ZnO film, Ultrasonic Spray Pyrolysis, Defect, optical

\section{INTRODUCTION}

$\mathrm{ZnO}$ is ceramic semiconductor material. It has interesting properties because of its wide bandgap energy (3.4 $\mathrm{eV})$ and it has also large exciton binding energy $(60 \mathrm{meV})[1,2]$. Their properties are also attractive because $\mathrm{ZnO}$ may be used in many devices such as devices in Photocatalytic, Optoelectronic, and Textile [3,4]. Previous research show that $\mathrm{ZnO}$ film have been carried out by many method such as molecular beam epitaxy (M.B.E.) [5], metal-organic chemical vapor deposition (MOCVD) [6], sputtering [7], pulsed laser deposition (PLD) [8], chemical vapor deposition (CVD) [9]. One these method is ultrasonic Spray Pyrolisis (U.S.P.) which is low cost and simple method to get a good $\mathrm{ZnO}$ films on many type of substrate [10]. ZnO ceramic materials show Photoluminescence phenomena in the U.V. and Visible region [11]. Previous results reported that these phenomena U.V. is originate from band to band transition and free exciton recombination [12], and the visible region may be predicted from the existence of native defect [13]. But, the mechanism the visible luminescence is unfinished.

Thermal annealing is a heating process at certain temperature for certain time. During annealing, the atom of the materials may move or diffuse in order to rearrange the position to have the lowest energy. Thermal annealing is usually 
used in a semiconductor material to activate the dopant and to improve crystal quality. In other research thermal annealing of undoped $\mathrm{ZnO}$ and doped $\mathrm{ZnO}$ films were conducted in various temperature and time [14]. Various defect, such as Vacancy, Interstitial, dislocation, and other structural defects may move in the bulk material and absorption/decomposition may also occur on the surface. Hence, the structure and stoichiometric ratio of the material may also change [14]. Therefore, all of these changes will affect Optical properties.

In this paper, we study the optical properties and the existence of defects of $\mathrm{ZnO}$ films grown on $\mathrm{Si}(111)$ substrate by the U.S.P. method. The phenomena of the defect is interesting to be studied because it may control the donor or acceptor in $\mathrm{ZnO}$ thin films [15].

\section{MATERIALS AND METHOD}

Zinc acetate dehydrate $\left[\mathrm{Zn}\left(\mathrm{CH}_{3} \mathrm{COO}\right)_{2} .2 \mathrm{H}_{2} \mathrm{O}\right]$ was used as a precursor materials. This materials was diluted in deionized water in concentration $(0.02 \mathrm{~mol} / \mathrm{ml})$. Ultrasonic Spray Pyrolisis (USP) was used to deposit ZnO solution on $p$ type $\mathrm{Si}(111)$ substrates. The aerosol of the precursor for each solution were then injected onto a $\mathrm{Si}$ (111) substrate while heated at temperature, $400^{\circ} \mathrm{C}, 450^{\circ} \mathrm{C}$, and $500^{\circ} \mathrm{C}$ for 10 minutes. Then, some of the samples were annealed at $800^{\circ} \mathrm{C}$ for 2 hours at atmosfer ambient. The structure, morphology, photoluminescense, optical absorbance of the non annealed and annealed $\mathrm{ZnO}$ films were characterized by using by X-ray diffraction (XRD 7000 Shimadzu), Transmission electron Microscope, Renishaw micro-PL system with $325 \mathrm{~nm}$ He-Cd laser as the excitation source, and spectrophotometer VisNIR ocean optics USB 1000 oceanoptic, respectively.

\section{RESULTS AND DISCUSSION}

\subsection{X-ray Diffraction}

X-ray diffraction were used to determine phase and the structure of the film. Figure 1 shows the XRD pattern of $\mathrm{ZnO}$ films grown by ultrasonic spray pyrolisis (USP) with growth temperatures $400^{\circ} \mathrm{C}, 450^{\circ} \mathrm{C}$, and $500^{\circ} \mathrm{C}$. It is seen that the non annealed and annealed $\mathrm{ZnO}$ films at $800^{\circ} \mathrm{C}$ for 2 hours shows the phase of $\mathrm{ZnO}$. There are seven diffraction peaks which observed at $2 \theta=31.7^{\circ}, 34.7^{\circ}, 36.3^{\circ}, 47.6^{\circ}, 56.5^{\circ}, 63^{\circ}, 68.1^{\circ}$. 

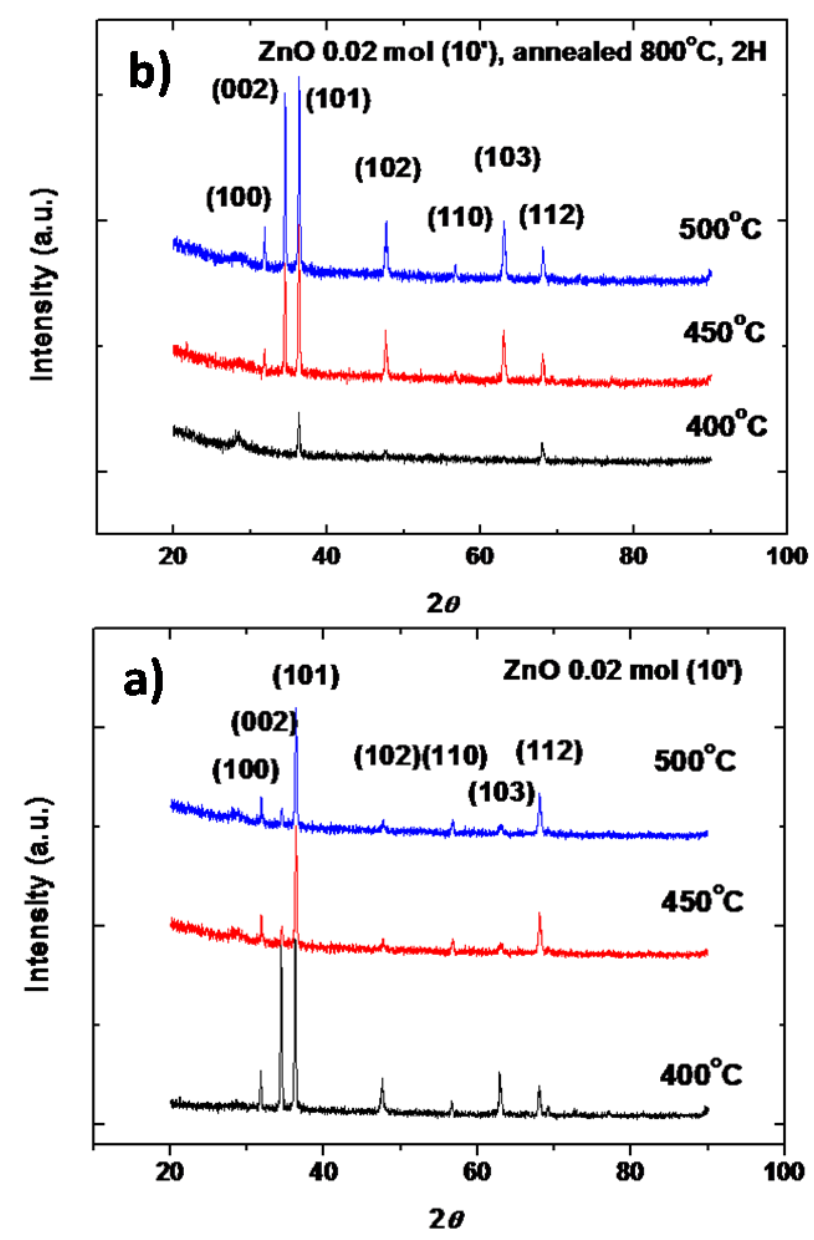

Figure 1 : XRD pattern of $\mathrm{ZnO}$ films $0.02 \mathrm{~mol}$ at growth temperatures $400^{\circ} \mathrm{C}, 450^{\circ} \mathrm{C}$, and $500^{\circ} \mathrm{C}$, a) non-annealed, b) annealed at $800^{\circ} \mathrm{C}$ for 2 hours

The peaks observed are related to (100), (002), (101), (102), (110), (103), (112) plane, respectively. The (002) and (101) plane of the $\mathrm{ZnO}$ film have the most higher peaks. Nevertheless, the peaks of $\mathrm{ZnO}$ thin films at growth temperature $400^{\circ} \mathrm{C}$ is reduced by annealing. It indicate that absorption/decomposition process during annealing may occur on the surface of $\mathrm{ZnO}$ films at growth temperature $400^{\circ} \mathrm{C}$.

\subsection{Transmission Electron Microscope (TEM)X-ray Diffraction}

Transmission Electron Microscope was used to observed the morphology, the phase and the ratio of $\mathrm{Zn}$ and Oxygen element. . Selected area electron diffraction (SAED) pattern which was taken from the corresponding area of $\mathrm{ZnO}$ deposit at temperature $450{ }^{\circ} \mathrm{C}$ and annealed at $800{ }^{\circ} \mathrm{C}$ for 2 hours is shown in Figure 2. JEMS software was used to identify the phase of the pattern. It reveals the presence of $\mathrm{ZnO}$, which correspond to ICSD 164690 crystallography base data. Small ring radius deviation detected on the SAED may indicate that the stochiometry does not fit $100 \%$ with $\mathrm{ZnO}$. It indicate the present of atomic defect.

The particle size and shows E.D.X. line scan was taken from one particle of $\mathrm{ZnO}$ (Figure 3). The particle has a size of around $20 \mathrm{~nm}$. The element concentration of $\mathrm{Zn}$ and Oxygen are not fit to $1: 1$ along the line. It indicates the existences of defect. 


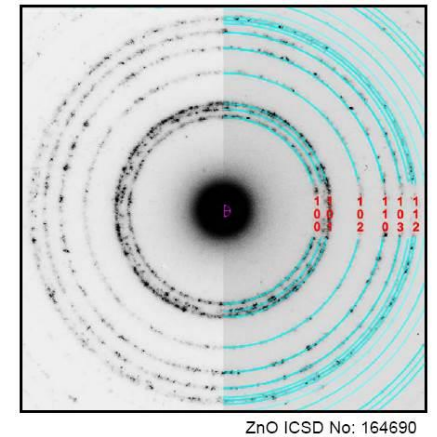

a

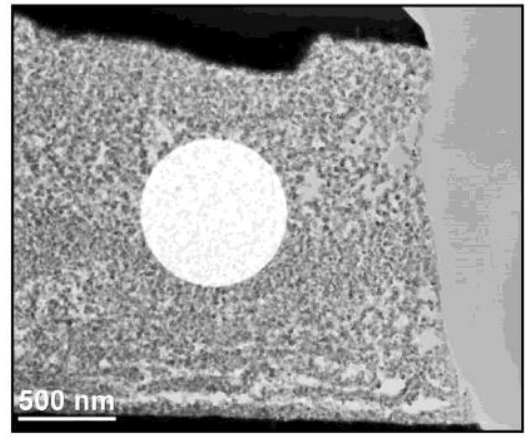

b

Fig. 2. Selected Area Electron Diffraction (SAED) (a) pattern taken from the corresponding area of $\mathrm{Zn}_{\mathrm{x}} \mathrm{O}_{\mathrm{y}}$ (b) deposit at temperature $450^{\circ} \mathrm{C}$ and annealed at $800{ }^{\circ} \mathrm{C}$ for 2 hours.

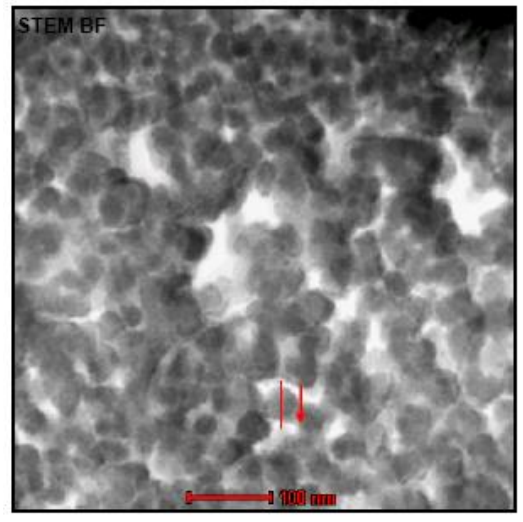

a

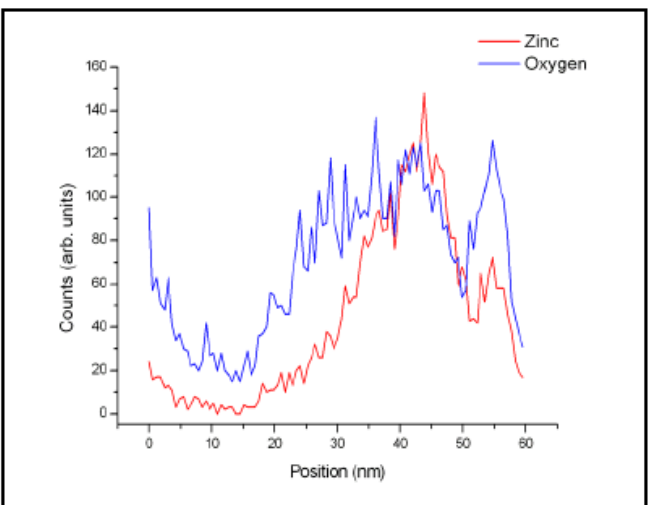

b

Figure 3. (a) Morphology of the $\mathrm{ZnO}$ film (b) E.D.X. Line scan taken from one particle of $\mathrm{Zn}_{\mathrm{x}} \mathrm{O}_{\mathrm{y}}$

From Figure $3 \mathrm{~b}$, It is seen that the concentration of Oxygen is higher than the concentration of $\mathrm{Zn}$. It indicate the present of $\mathrm{Zn}$ Vacancy.

\subsection{Photoluminescence (PL)}

Photoluminescence is a process where a molecule absorbs a photon in the visible region. It is exciting one of its electrons to a higher electronic excited state, and then radiates a photon when the electron returns to a lower energy state. Photoluminescence spectroscopy is a technique for characterization of the optical and electronic properties of materials.

The room temperature PL for un-annealed and annealed of $\mathrm{ZnO}$ films is shown in Figure 2. It shows $\mathrm{ZnO}$ film properties which consists of narrow UV peaks at around $\sim 380 \mathrm{~nm}$ and broad deep level peak at around 510-600 $\mathrm{nm}$ 


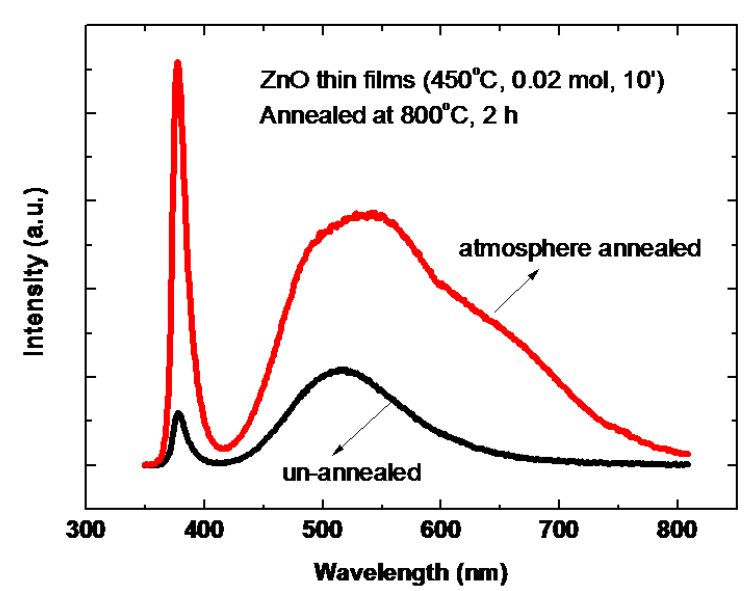

Figure 2 : Room temperature PL spectra of non annealed and annealed at $800^{\circ} \mathrm{C}$ for 2 hours

The peak at around $\sim 380 \mathrm{~nm}$ may due to free exciton recombination process which can be related to the interface traps that exist in the grain boundaries. The strong green band may be due to the presence of defect (deep level emission), appear as broad peak at around 510-600 nm.

The deep level emission might probably relative variations of the instrinsic defects in $\mathrm{ZnO}$ films $[14,15,16]$. These defects generally are zinc vacancy $\mathrm{V}_{\mathrm{Zn}}$, oxygen vacancy $\mathrm{V}_{\mathrm{O}}$, interstitial zinc $\mathrm{Zn}_{\mathrm{i}}$, interstitial oxygen $\mathrm{O}_{\mathrm{i}}$, and antisite oxygen $\mathrm{O}_{\mathrm{Zn}}$ [Error! Bookmark not defined.].

Sun had calculated energy level of $\mathrm{ZnO}$ tfilms by applying the full potential linear muffin-tin orbital method [Error! Bookmark not defined.,17]. Meanwhile, Fan found that the electron transitions from the bottom of the conduction band to the antisite oxygen $\mathrm{O}_{\mathrm{Zn}}$ and the interstitial oxygen $\mathrm{O}_{\mathrm{i}}$ defect levels should mainly contribute to the deep level emission of PL spectra of $\mathrm{ZnO}$ films [Error! Bookmark not defined.].

\subsection{Vis-NIR}

Vis-NIR Spectroscopy is based on the absorption visible-NIR light by chemical compounds. The absorption spectra of undoped $\mathrm{ZnO}$ films at growth temperatures $400^{\circ} \mathrm{C}, 450^{\circ} \mathrm{C}$, and $500^{\circ} \mathrm{C}$, for non annealed, and annealed at $800^{\circ} \mathrm{C}$ for 2 hours are shown in Figure 3. Using Planck's equation $E=h v$, the absorption spectra peaks, the defect's energy level of $\mathrm{ZnO}$ films can be determined. The calculated energy interval of $\mathrm{ZnO}$ films grown by USP is relative to the electronics transition from the bottom of conduction band to the $\mathrm{O}$ vacancy $\left(\mathrm{V}_{\mathrm{O}}\right)$, $\mathrm{O}$ interstitial $\left(\mathrm{O}_{\mathrm{i}}\right)$, and antisite $\mathrm{O}\left(\mathrm{O}_{\mathrm{i}}\right)$.

The defect's energy level of ZnO films grown by USP is shown on Table 1. It is shown that the defect's energy level varies non linearly for the samples non annealed and annealed for each growth temperatures.

The calculated energy interval of deep level emission is shown on Table 2 . The Table 1 and Table 2 show the defect's energy level of $\mathrm{ZnO}$ film growth at temperature $500^{\circ} \mathrm{C}$ with annealed $800^{\circ} \mathrm{C}$ for 2 hours coincide with the energy interval of deep level emission $(1.62 \mathrm{eV})$. It might be attributed to the electronic energy transition from the bottom of conduction band to the oxygen vacancy (Vo) energy level, $1.62 \mathrm{eV}$. It is common known that substrate Si is easy to be oxidized [18], so the interface layer $\mathrm{SiO}_{2}$ which is formed between $\mathrm{Si}$ and $\mathrm{ZnO}$ layer, is increase in oxygen vacancy $\left(\mathrm{V}_{\mathrm{o}}\right)$. Furthermore, by increasing oxygen vacancy $\mathrm{V}_{\mathrm{o}}$ can suppress the concentraton amount of antisite oxygen in ZnO films [Error! Bookmark not defined.]. 

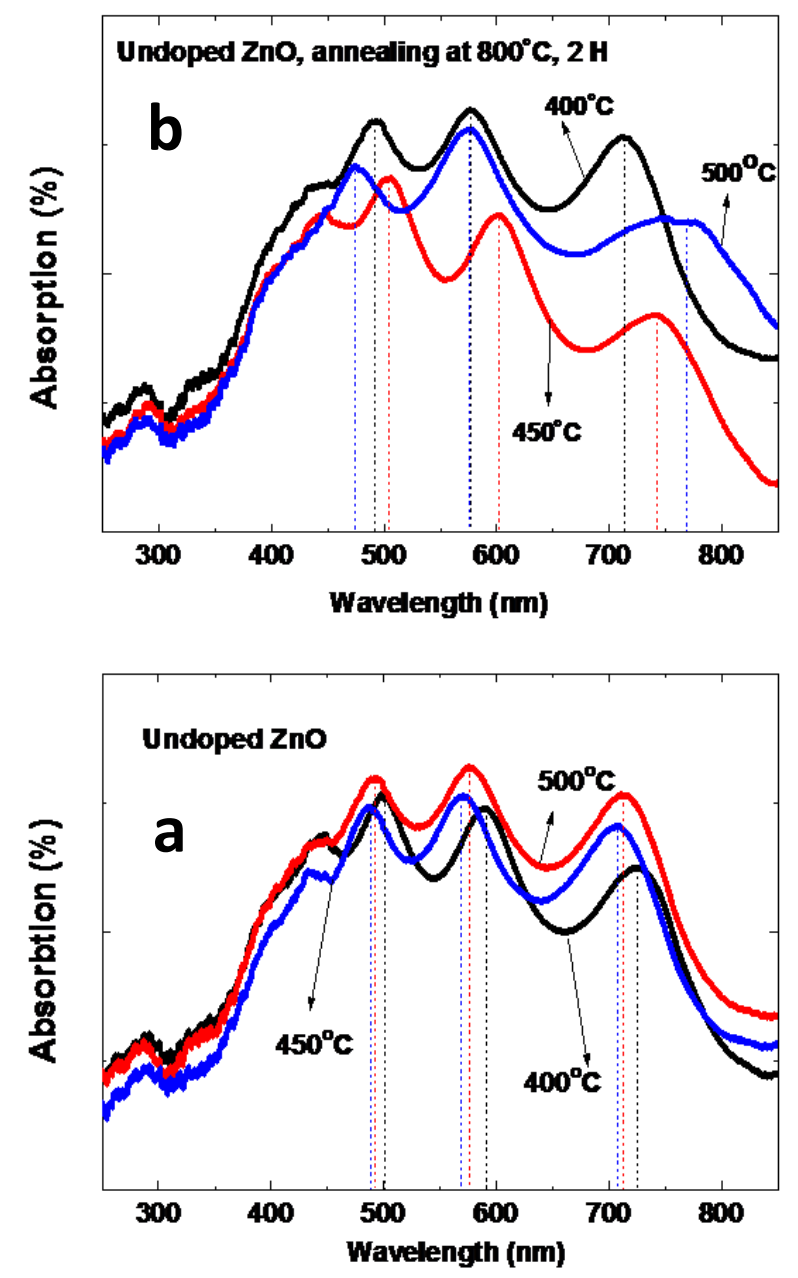

Figure 3 : Absorption spectra of undoped $\mathrm{ZnO}$ thin films at growth temperatures $400^{\circ} \mathrm{C}, 450^{\circ} \mathrm{C}$, and $500^{\circ} \mathrm{C}$, a) non annealed, b) annealed at $800^{\circ} \mathrm{C}$ for 2 hours

Table 1:. Defect's energy level of $\mathrm{ZnO}$ thin films grown by USP

\begin{tabular}{|c|c|c|c|c|c|c|}
\hline \multirow[b]{3}{*}{ No } & \multicolumn{2}{|c|}{$400^{\circ} \mathrm{C}$} & \multicolumn{2}{|c|}{$450^{\circ} \mathrm{C}$} & \multicolumn{2}{|c|}{$500^{\circ} \mathrm{C}$} \\
\hline & \multicolumn{6}{|c|}{$\mathrm{E}(\mathrm{eV})$} \\
\hline & $\begin{array}{c}\text { Non- } \\
\text { Annealed }\end{array}$ & Annealed & $\begin{array}{c}\text { Non- } \\
\text { Annealed }\end{array}$ & Annealed & $\begin{array}{c}\text { Non- } \\
\text { Annealed }\end{array}$ & Annealed \\
\hline 1 & 2.49 & 2.53 & 2.55 & 2.46 & 2.53 & 2.62 \\
\hline 2 & 2.10 & 2.16 & 2.18 & 2.07 & 2.16 & 2.16 \\
\hline 3 & 1.71 & 1.74 & 1.76 & 1.68 & 1.74 & 1.62 \\
\hline
\end{tabular}

Meanwhile, the other defect's energy level are not coincidence with the energy interval of deep level emission. It can be predicted that the defect's energy interval between 2.16 up to $2.18 \mathrm{eV}$ might be originate from oxygen interstitial $\left(\mathrm{O}_{\mathrm{i}}\right)$ and the defect's energy level around $2.5 \mathrm{eV}$ (2.46 up to $2.55 \mathrm{eV})$ might be originate from the electron energy transition from the level of the ionized oxygen vacancies to the valence band level [19]. Ionized vacancies is believed to be responsible for the green emission in $\mathrm{ZnO}$ films [20]. 
Table 2 :. The energy interval of $\mathrm{ZnO}$ film deep level emission [14, 17]

\begin{tabular}{|c|c|c|}
\hline $\begin{array}{c}\text { Defect's } \\
\text { energy (eV) }\end{array}$ & \multicolumn{2}{|c|}{ Intrinsic defect } \\
\hline 1.62 & $\mathrm{~V}_{\mathrm{o}}$ & O vacancy \\
\hline 2.28 & $\mathrm{O}_{\mathrm{i}}$ & O interstitial \\
\hline 2.38 & $\mathrm{O}_{\mathrm{zn}}$ & Anti site $\mathrm{O}$ \\
\hline 2.9 & $\mathrm{Zn}_{\mathrm{i}}$ & Zn Interstitial \\
\hline
\end{tabular}

\section{CONCLUSION}

The $\mathrm{ZnO}$ films have been coated on $\mathrm{Si}$ (111) substrate by ultrasonic spray pyrolisis (USP) at various growth temperatures $400^{\circ} \mathrm{C}, 450^{\circ} \mathrm{C}$, and $500^{\circ} \mathrm{C}$ succesfully. The annealed were performed for each $\mathrm{ZnO}$ films at temperature $800^{\circ} \mathrm{C}$ for 2 hours. The XRD spectra show that a $\mathrm{ZnO}$ thin film has polycrystalline structure. The $\mathrm{ZnO}$ films show a typical luminescence behaviour. The defect's energy level 1.62 eVshould be attributed to the electronic transition from the bottom of conduction band to the oxygen vacancy (Vo). The defect's energy interval about 2.16 up to $2.18 \mathrm{eV}$ originate from oxygen interstitial (Oi) and the defect's energy level about $2.5 \mathrm{eV}$ (2.46 up to $2.55 \mathrm{eV})$ originate from the electron transition from the level of the ionized oxygen vacancies to the valence band.

\section{ACKNOWLEDGEMENT}

The authors would like to thanks for the financial support from Government of Indonesia, through Grant Penelitian Dasar Unggulan Perguruan Tinggi (PDUPT), No. 366/UN2.R3.1/HKPO5.00/2018, Kementrian Riset Teknologi dan Pendidikan

\section{REFERENCES}

[1] M.A Borysiewicz, ZnO as a Functional Materials: A Review , Crystals, 9(10), 505, 2019

[2] X. W. Sun and H. S. Kwok, J. Appl. Phys. 86, 408-411 (1999)

[3] Segawa Y, Ohtomo A, Koinuma M, Tang ZK, Yu P, Wong GKL., Phys Stat Sol (b), 202:669 (1997)

[4] S.T. Tan, B. J. Chen, X. W. Sun, W. J. Fan, H. S. Kwok, X. H. Zhang and S. J. Chua, J. App. Phys. 98, 013505 (2005)

[5] K.K. Kim, J.H. Song, H.J. Jung, W.K. Choi, S.J. Park, J.H., Song, J. Appl. Phys. 87, 3573(2000).

[6] X. W. Sun and H. S. Kwok, J. Appl. Phys. 86, 408 (1999)

[7] N. Izyumskaya, V. Avrutin, U. Ozgur, Y.I. Alivov, and H. Morkoc, Phys. stat. sol. (b) 244, , p. 1439-1450 (2007)

[8] J.L. Zhao, X.W. Sun, S.T. Tan, G.Q. Lo, D.L. Kwong, Z.H. Cen, Appl. Phys. Lett. 91, 263501 (2007).

[9] S. Iwan, S. Bambang, J. L. Zhao, S. T. Tan, X. W. Sun, G.Q. Lo, H. M. Fan, L. Sun, S. Zhang, Physica B, 407, 2721-2724 (2012)

[10]P.T. Hsieh, Y.C. Chen, K.S. Kao, M.S. Lee, C.C. Cheng, J. European Ceramic Society, 27, 3815-3818 (2007)

[11] A. van Dijken, E.A. Meulenkamp, D. Vanmaekelbergh, A. Meijerink, J. Luminescence 20, 123-128 (2000)

[12] Q.P. Wang, D.H. Z.Y. Z.Y. Xue, and X.T. Hao, Appl. Surface Science 201, p.123-128 (2002)

[13]D. C. Look, B. Claflin, Ya. I. Alivov, and S. J. Park, phys. stat. sol. (a) 201, 2203-2212 (2004).

[14]X.M. Fan, J.S. Lian, Z.X. Guo, and H.J. Lu, Appl. Surface Science 239, p.176-181 (2005)

[15] B. Lin, Z. Fu, Y. Jia, Appl. Phys. Lett. 79, 943 (2001)

[16] M. Liu, A.H. Kitai, P. Mascher, J. Luminescence 54, 35 (1992)

[17] Y.M. Sun, Ph.D. Thesis, University of Science and Technologyof China (2000).

[18] Iwan Sugihartono, Bambang Soegijono, M. Hikam, E. Handoko, Fan H.M, S.T. Tan, X.W. Sun, 2013 International Confrence on QiR, p. 232-234 (2013)

[19] D.H. Zhang, Z.Y. Xue, Q.P. Wang, J. Ma, Proc. SPIE 4918, 425 (2002)

[20] K. Vanheusden, W.L. Warren, C.H. Seage, D.R. Tallent, J.A.Voigtang, B.E. Gnade, J.Appl. Phys. 79, 7983 (1996). 